NBER WORKING PAPER SERIES

ECONOMIC CONSEQUENCES OF UNFUNDED

VESTED PENSION BENEFITS

Mark Gersovitz

Working Paper No. $\underline{480}$

NATIONAL BUREAU OF ECONOMIC RESEARCH 1050 Massachusetts Avenue Cambridge MA 02138

May 1980

I would like to thank participants at the NBER Social Insurance and Pensions Conference, January 7-9, 1980, especially Benjamin M. Friedman, for valuable comments. Financial support for the research reported in this paper was received from the S.S. Huebner Foundation for Insurance Education, Wharton School, University of Pennsylvania. The research reported here is part of the NBER's research program in Pensions. Any opinions expressed are those of the author and not those of the National Bureau of Economic Research. 


\title{
Economic Consequences of Unfunded
}

Vested Pension Benefits

\begin{abstract}
This paper examines the relationship between unfunded vested pension liabilities and the market value of a firm's shares. This relationship has important implications for the mechanism by which private pensions influence aggregate savings. Attention is paid to modeling the institutional determinants of this relation implied by ERISA legislation. These considerations require a nonlinear regression model with very special properties which are developed and discussed. Estimation results suggest that ERISA has had an important effect on the relation between unfunded benefits and firm value that previous investigations have neglected.
\end{abstract}

Mark Gersovitz Department of Economics Princeton University Princeton, New Jersey 08544

(609) $452-4794$ 
This paper examines the effect of unfunded vested pension liabilities $^{1}$ on the market value of a firm's shares. The nature of this relationship has important implications for several aspects of the policy debate on the private pension system and its reform. As Feldstein (1978) has stressed, the extent to which unfunded pension liabilities affect stock market values (MV) is a critical linkage in the mechanism by which private pensions influence aggregate saving. If, for instance, pension liabilities lower the stock value on a dollar for dollar basis, then the disincentive to save given to potential pensioners by an additional dollar of unfunded benefits is exactly offset by the incentive to save given to stock holders by the loss of a dollar in stock value. Aggregate saving is not altered. At the other extreme, unfunded liabilities may have no impact on stock values. In this case there is no incentive for additional saving to offset any decrease in saving by pensioners. Another important concern involves the large potential liabilities undertaken by a U.S. government agency under the ERISA pension reforms legislation. Beyond certain limits, the Pension Benefit Guarantee Corporation (PBGC) relieves private employers of their responsibility for unfunded vested pension benefits (UVB). An examination of the market valuation effects of these UVB can yield evidence on the opinion of stock market participants about the potential financial drain on the badly undercapitalized PBGC. Finally, there has been considerable concern over the accuracy of reporting by firms of their pension liabilities. The relation between $M V$ and UVB can be used to infer the view of market participants about the reliability of financial reporting. This evidence has implications for the reform of pension reporting. 
In Section 1 of the paper I discuss the institutional and theoretical determinants of the relation between unfunded pension liabilities and the stock market. value of a firm's shares. Section 2 develops, an econometric method appropriate to the estimation of this relationship. Section 3 presents and discusses the empirical results. 
1. The Effect of Unfunded Vested Pension Benefits on the Market Value of a Firm

Prior to 1974, firms were not legally liable for unfunded vested pension benefits. A firm could terminate a plan and employees with vested pension benefits would receive payment only insofar as the pension fund was adequate. Termination, however, would imply the need to compensate employees in another form over the long-run if the firm were to stay attractive in the labor market. Since compensation through pensions has tax advantages (Tepper, 1974) and helps control labor turnover costs (Schiller and Weiss, 1979) most firms continued their plans. In situations where there was no need to undertake alternative compensation, termination of a plan could be an attractive option. The Studebakex Corporation, for instance, terminated its under-funded plan at the same time it ended automobile production. Thus the funding decision embodies elements of risk sharing and implicit contracting between the owners of a firm and its employees (Arnott and Gersovitz, forthcoming).

In 1974, ERISA established a limited legal responsibility on the part of firms for their unfunded pension benefits. An employer became liable for the minimum of its total unfunded vested pension benefits (UVB) or 30 percent of its net worth defined as the stock market value of its shares (MV). A government sponsored corporation, the PBGC, became liable for any excess of UVB over . 3MV up to certain limits beyond which employees were left unprotected. The PBGC was also given the right to terminate any plan which it felt might involve the PBGC in additional liabilities. Further, the PBGC can 
determine the value of the firm for purposes of calculating the employer's liability at any point within a 120 day period around the termination date (the window). 2

Against this background it is possible to develop an equation for the market value of a firm with unfunded pension liabilities. If $.3 \mathrm{MV}>\mathrm{UVB}$, it is almost certain that the firm will eventually pay the full value of UVB into the pension fund. If the market value of the firm begins to deteriorate so that . 3MV approaches UVB, the PBGC will either terminate the plan or negotiate with the firm to fund enough of the UVB to maintain . 3MV > UVB. Using the 120 day window, the PBGC should have no difficulty making the firm satisfy this condition. It would be impossible to realize the full value of UVB only if the firm's value plunged past the . 3MV $=$ UVB threshold, to a situation where UVB > MV, before the PBGC could act. Except for this highly unlikely situation, a firm with . 3MV > UVB should have the valuation equation:

$$
\mathrm{MV}=\mathrm{PVE}-\mathrm{UVB} \quad .3 \mathrm{MV}>\mathrm{UVB}
$$

where PVE is the present value of earnings after all other charges (interest, preferred dividends etc.) other than UVB.

For firms with UVB $>.3 M V$, however, the situation is more complicated. These firms have the option of terminating their own plans for a payment of .3MV. The firm need not be bankrupt in any sense to exercise this option. Further, the PBGC may wish to terminate these plans to avoid further losses. If the plan were definitely known to be on the verge of termination, the value of the firm's shares would be given by 


$$
\mathrm{MV}=\mathrm{PVE}-\mathrm{UVB}+(\mathrm{UVB}-.3 \mathrm{MV}) \quad .3 \mathrm{MV}<\mathrm{UVB}
$$

where UVB - .3MV appears as an implicit asset.

At present, however, there are many plans satisfying . $3 \mathrm{MV}<\mathrm{UVB}$ which do not seem to be in imminent danger of termination. For these firms there is always the chance that PVE will stochastically move so that $.3 M V>$ UVB in the future. To take this possibility into account requires an option pricing approach in specifying the market value equation (Sharpe, 1976) which is so complicated as to be intractable (Smith, 1976). As a practical specification of the effect of UVB on MV, I therefore adopt the approximation of equations $-(1)$ and (2):

$$
M V= \begin{cases}\text { PVE }- \text { UVB } & \text { if . } 3 M V \geq U V B \\ \text { PVE }-U V B+(U V B-.3 M V) & \text { if . } 3 M V<U V B\end{cases}
$$

For estimation, this model is specified as

$$
\mathrm{MV}= \begin{cases}\mathrm{PVE}+\mathrm{\gamma}_{1} \mathrm{UVB} & .3 \mathrm{MV} \geq \mathrm{UVB} \\ \mathrm{PVE}+\mathrm{\gamma}_{1} \mathrm{UVB}+\gamma_{2}(.3 \mathrm{MV}-\mathrm{UVB}) \cdot .3 \mathrm{MV}<\mathrm{UVB}\end{cases}
$$

and I test the joint restriction that $\gamma_{1}=-1$ and $\gamma_{2}=1$. 


\section{Econometric Method}

Estimating the effect of pension liabilities on market value, given the institutional structure represented by ERISA, is a coinplicated problem. The use of conventional ordinary least squares is inappropriate because the dependent variable appears on both sides of the estimating equation. Consider the stochastic behavior described by

$$
y_{i}=A x_{i}+\alpha z_{i}+B w_{i}+v_{i} \quad \text { if } w_{i}>0
$$

$$
y_{i}=A x_{i}+\alpha z_{i}+v_{i}
$$

(4c)

$$
w_{i}=z_{i}-\delta y_{i}
$$

where $A$ is $1 \times k$ vector of unknown coefficients, $x_{i}$ is a $k \times 1$ vector of exogenous variables, $z_{i}$ is an additional exogenous variable, $\alpha$ and $\beta$ are unknown coefficients and $\delta$ is a known parameter. The error term, $v_{i}$, is assumed to be independently normally distributed with constant variance $\sigma^{2}$.

Since $\delta$ is known, the sign of the expression $z_{i}-\delta y_{i}$ can be ascertained. Any set of $\mathrm{N}$ observations can therefore be partitioned with the first $n$ known to have been generated by equation (4a) while the remaining $N$ - $n$ are known to have been generated by equation (4b). If all observations were generated by equation ( $4 b$ ) so that $n=0$, estimation is quite straightforward since the assumptions necessary for ordinary least squares are satisfied. Unfortunately the estimation of equation (4b) alone provides no 
estimate of the parameter $B$.

Equation (4a) by itself, however, poses one immediate difficulty. The variable $w_{i}$ is endogenous since it involves $y_{i}$, and $w_{i}$ appears on the righthand side of the equation. Consequently, (4a) could not be estimated by ordinary least squares. To correct this problem, substitute in (4a) from (4c) for $w_{i}$, collect terms and rewrite the equation as

$$
y_{i}=\frac{A x_{i}+(\alpha+\beta) z_{i}}{1+\delta \beta}+\frac{v_{i}}{1+\delta \beta} \quad \text { if } w_{i}>0
$$

A second problem immediately arises if all observations satisfied $w_{i}>0$. Whille equation ( $\left.4 a^{\prime}\right)$ could be estimated by ordinary least squares, the parameters of the model $A, \alpha$ and $\beta$ would not be identified. Instead, only the composite parameters $A /(1+\delta \beta)$ and $(\alpha+\beta) /(1+\delta \beta)$ would be identified.

If however, there are observations for which $w_{i}>0$ and for which $w_{i} \leq 0$, i.e. $N>n>0$, estimation of the model is possible and all parameters can be identified. It is the cross-equation constraints [the fact that the $A$ and $a$ are the same in equations (4a) and (4b)] which identify the coefficients. An ordinary least squares procedure is no longer appropriate and a maximum likelihood formulation must be used. The estimation problem is similar to that encountered in Tobit (Tobin, 1956) and switching regressions (Goldfeld and Quandt, 1973) although it has its own unique structure.

The likelihood of $z_{i}$ for $0<i \leq n$ is given by

$$
L_{i}=\frac{1+\delta \beta}{\sqrt{2 \pi} \sigma} \exp \left[-\frac{1}{2}\left\{\frac{y_{i}-A x_{i}-(\alpha+\beta) z_{i}}{.1+\delta \beta}\right\}^{2} \frac{(1+\delta \beta)^{2}}{\sigma^{2}}\right] \text {. }
$$

The likelihood of $y_{i}$ for $N \geq i>n$ is given by 


$$
L_{i}^{\prime}=\frac{1}{\sqrt{2 \pi} \sigma} \exp \left[-\frac{1}{2} \frac{\left(y_{i}-A x_{i}-\alpha z_{i}\right)^{2}}{\sigma^{2}}\right] \text {. }
$$

Thus, the likelihood for the entire sample is

$$
L=\left(\prod_{i=1}^{n} L_{i}\right) \quad\left(\prod_{i=n+1}^{N} L_{i}^{\prime}\right)
$$

Maximization of equation (6) with respect to the parameters of the model yields the estimates of these parameters. [This maximization was undertaken at Princeton University in double precision FORTRAN. The method of maximization was the GRADX option of the GQOPT program based on the method of quadratic hill-climbing (Goldfeld, Quandt and Trotter, 1966)]

A final aspect of this econometric model which deserves special attention is the problem of consistency. Given a set of observations on the $y_{i}$ and $z_{i}, w_{i}$ can be formed and used to classify the observations. The estimation can then proceed as described. However, since the $w_{i}$ is unknown until the $y_{i}$ is generated, and the $y_{i}$ cannot be known until the $w_{i}$ is known, the model of (4a) - (4c) is not a fully satisfactory formulation. A consistent and complete reformulation is

(7a)

$$
y_{1}=A x+\alpha z+B w_{1}+v
$$

$$
y_{2}=A x+a z+v
$$

$$
w_{1}=z-\delta y_{1}
$$


(7d)

$$
w_{2} \doteq z-\delta y_{2}
$$

(7e)

$$
y=y_{1}
$$

$$
w_{1}>0 \text { or } w_{2}>0
$$

$$
y=y_{2}
$$

$$
w_{1} \leq 0 \text { or } w_{2} \leq 0
$$

where the subscript $i$ has been suppressed and the variable y corresponds to the $y_{i}$ of (4).

Consistency requirements for this model are that

$$
w_{1}>0 \text { iff } w_{2}>0
$$

or

$$
w_{1} \leq 0 \quad \text { iff } w_{2} \leq 0 .
$$

If these conditions were not met, then a situation could arise where the model of (7) implied (7e) and (7f) at the same time, an inconsistency unless $\beta=0$. To express the consistency conditions in terms of the underlying parameters of the model, substitute for $w_{1}$ in (7a), collect terms, solve for $y_{1}$ and substitute $y_{1}$ into $w_{1}$ to yield

$$
w_{1}=\frac{z-\delta A x-\delta \alpha z-\delta y}{1+\delta \beta}
$$

Substituting (7b) into $w_{2}$ yields 
(9b)

$$
w_{2}=z-\delta A x-\delta a z-\delta v .
$$

Hence

$$
w_{1}=w_{2} /(1+\delta \beta) .
$$

From (9c) it is clear that a necessary and sufficient condition for $w_{1}$ and $w_{2}$ to have the same sign is that

$$
1+\delta B>0
$$

henceforth referred to as the consistency condition for the mode1 (7). In particular if $\delta$ and $\beta$ are both positive, the model is consistent. In this case, it does not matter whether $y_{1}$ or $y_{2}$ is used in the calculation of $w_{i}$ of model (4), and so model (4) provides a complete characterization of the estimation problem.

To summarize, the estimation procedure is

(a) form the $w_{i}$ using (4c)

(b) classify the observations into two groups with the first $n$ observations having $w_{i}>0$ and the last $N$ - n observations having $w_{i} \leq 0$

(c) form the likelihood function (6) using (5a) and (5b)

(d) maximize the likelihood to yield estimates of the mode1 parameters

(e) check the consistency requirement $1+\delta \beta>0$. 
3. Econometric Estimates of the Effect of UVB on MV

Following the discussion of Section 1, the basic equations determining the valuation of a firm's shares are:

(11a)

$$
\frac{M V}{A}=r_{0}+\frac{1}{\rho} \frac{e}{A}+r_{1} \frac{U V B}{A}+u \quad \text { if } w<0
$$

and

$$
\frac{M V}{A}=\left[\gamma_{0}+\frac{1}{\rho} \frac{e}{A}+\left(\gamma_{1}+r_{2}\right) \frac{U V B}{A}+u\right] \quad \frac{1}{1+.3 \gamma_{2}} \quad \text { if } w>0
$$

where

$$
w=U V B-.3 M V
$$

and

$$
\rho=\rho_{0}+\rho_{1} B
$$

MV is the year-end value of outstanding common shares obtained from the Compustat tapes.

Total earnings, e, are given by the 3-5 year forecast of the Value Line Investment Survey closest to December multiplied by the total number of common shares from the Compustat tapes. This earnings measure 


\section{TABLE 1}

\section{Stock Valuation Equation}

Coefficient

ro

po

$\rho_{1}$

$r_{1}$

Y2

Value of

the Log

Likelihood
Variant 2

$-.298$

(7.03)

(6.32)

.099

(12.77)

$-.0023$

(.33)

$-2.25$

(4.59)

2.76

(4.11)

6.22

$-.0060$

(.85)

$-.674$

(2.21)
Variable

constant

discount rate constant

B

UVB

UVB

if . $3 M V>U V B$

Note: Upper row gives coefficient, lower row gives coefficient divided by its asymptotic standard deviation.

Sample consists of 217 Fortune 500 companies chosen on the basis of data availability. Seventeen companies have UVB $>$.3MV. 
does not include charges for the amortization of unfunded vested benefits. Results based on the Value Line forecast ${ }^{3}$ rather than an extrapolation of current and past earnings are presented because Malkiel and Cragg (1970) provide evidence that the market opinion approach is superior in valuation equations. I also used current earnings with similar results to those reported in Table 1 for the coefficient estimates but with much lower values of the likelihood function.

The discount rate, $\rho$, incorporates $B$, the Value Line calculation of the Sharpe Beta for the firm. This term provides the most common representation of a risk adjusted discount rate (Fama, 1977). UVB measures unfunded vested benefits as given by the Compustat tapes. The variables MV, $e$ and UVB are divided by the book-value of total assets A (from the Compustat tapes) to correct for heteroscedasticity. 4

Turning to the estimated values of $r_{1}$, it is clear that unfunded pension liabilities lower the value of a firm's shares. Further, unfunded liabilities above the PBGC threshold of 30 percent are added back as an asset since $\hat{\gamma}_{2}$ is positive. Recall from Section 2 that a positive value of $\gamma_{2}$ was sufficient for the stochastic system generating the data to be $\operatorname{logi-}$ cally consistent. It is also roughly true that $\hat{\gamma}_{1}+\hat{\gamma}_{2}=0$. Consequently, liabilities above. $3 \mathrm{MV}$ added back in such a way that the net effect of these additional liabilities is zero.

All these aspects of the estimated coefficients are consistent with the model of pension liabilities and market valuation elaborated in Section 1 , however, the absolute magnitudes of the estimated coefficients appear too high. Thus, while one expects that liabilities would dimimish the market value of an earnings stream on the dóllar for dollar basis, i.e. $\gamma_{1}=-1$, the estimated 
coefficients indicate that every dollar of liabilities diminishes market value by more than two dollars. The hypothesis that $\gamma_{1}+\gamma_{2}=0$ and $\gamma_{1}=-1$ can be rejected at less than the one percent level of significance using a likelihood ratio test ( $\log$ of the constrained likelihood $=2.19$ ). It appears that the simple model of Section 1 is rejected and that additional considerations must be investigated to understand the role of pension liabilities in firm valuation. 5

First, it is important to relate these results to the findings of an earlier study of this topic by oldfield (1977). Oldfield looked at the effect of pension liabilities on the stock value of firms, but failed to consider the institutional framework of the PBGC of Section 1 assuming $r_{2}=0$. In other respects, oldfield's specification is basically similar to the one used here. Within the framework of Variant $1, r_{2}=0$ is easily imposed yielding the Variant 2 estimates of Table 1. The effects are quite dramatic; the estimate of $\gamma_{1}$ falls in absolute magnitude to somewhat less than one. This estimate is insignificantly different from one and significantly different from zero. This result suggests a simple explanation for the effect of pension liabilities as a dollar for dollar subtraction from the valuation of earnings, as argued by oldfield using estimates similar to those of Variant 2.

But the Variant 1 equation makes it obvious that this simple formulation is entirely unsatisfactory. It is clear that Variant 2 is indeed a special case of Variant 1 obtained by restricting $\gamma_{2}$ to zero; Variant 2 is nested within Variant 1 and the t-statistic on $\gamma_{2}$ in Variant 1 directly tests the appropriateness of a Variant 2 specification. Given the magnitude of these t-statistics a Variant 2 formulation must be rejected 
since $\gamma_{2}$ is in all cases highly significantly different from zero.

The superficial consistency of a Variant 2 model with the dollar for dollar penalization of the present value of earnings is merely a statistical artifact. Consider a model where $\gamma_{1}<0$ and $\gamma_{1}+\gamma_{2}=0$. For simplicity, represent the effects of $\gamma_{0}, \rho$ and $e$ by the variable PVE, the present value of earnings. Thus the equations of the model are

$$
\begin{array}{ll}
\mathrm{MV}=\mathrm{PVE}+\gamma_{1} \mathrm{UVB} & \text { if } .3 \mathrm{MV}>\mathrm{UVB} \\
\mathrm{MV}=\frac{\mathrm{PVE}}{1+.3 \gamma_{2}}+\frac{\left(\gamma_{1}+\gamma_{2}\right) \mathrm{UVB}}{1+.3 \gamma_{2}} & \text { if . } 3 \mathrm{MV}<\mathrm{UVB}
\end{array}
$$

or

$$
\mathrm{MV}=\frac{\mathrm{PVE}}{1+.3 \gamma_{2}}
$$$$
\text { if . } 3 \mathrm{MV}<\mathrm{UVB}
$$

since $\gamma_{1}+r_{2}=0$.

Consider Figure 1, in which line segment $A B C$ gives the relation between UVB and MV if PVE is constant and assume that all firms.in a hypothetical cross-section have the same. PVE but different values of UVB. Since there is an error term in the relation between UVB and MV, the hypothetical cross section might consist of a set of points as pictured. If $\gamma_{2}$ is assumed to equal zero, then a regression line of the form EF will be estimated rather than one of the form $A B C$. The estimated value of $\gamma_{1}$ will be biased toward zero. The severity of this bias will depend on the number of companies for 


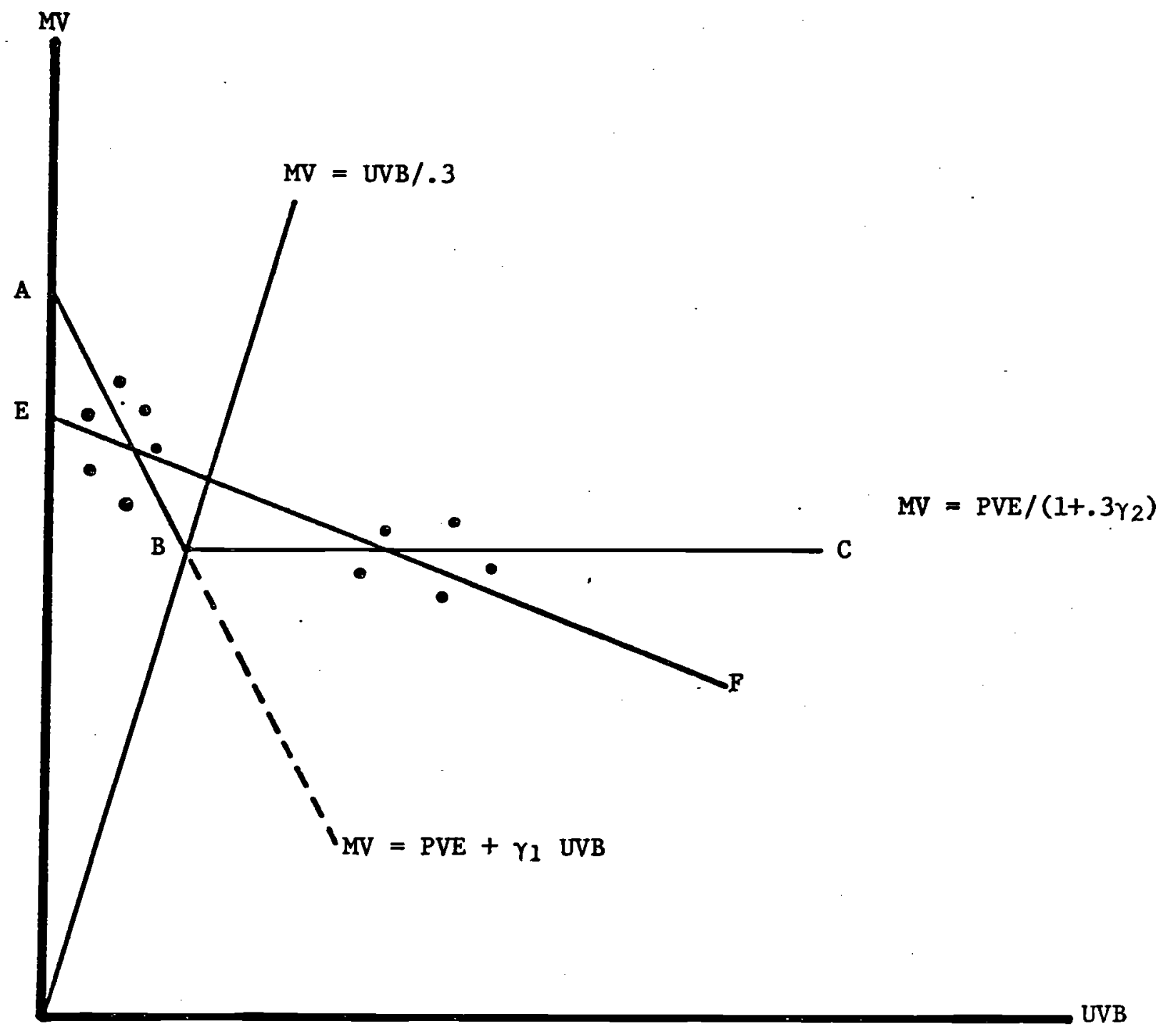


which UVB $>.3 M V$ and the magnitude of UVB - .3MV. It would appear that a specification error of this form is .responsible for the otherwise seemingly plausible results of oldfield.

As mentioned above, the estimated value of $\gamma_{1}$ is inconsistent with the valuation discussion of Section 1 which incorporates a literal reading of the ERISA provisions on unfunded benefits. Several plausible explanations of these results can be considered.

The simplest explanation of the large absolute values of $\hat{\gamma}_{1}$ and $\hat{\gamma}_{2}$ is that unfunded vested benefits have been systematically understated. 6 Let $\mu_{1}<1$ be the percentage by which pension liabilities are understated. For convenience, assume that $\mu_{1}$ is constant across companies. Further, assume that the PBGC bases its decisions on the true value of unfunded benefits rather than on the reported value. The model of (11) is then modified to

$$
S=P V E+\frac{r_{1}}{\mu_{1}} \text { UVB }
$$

$$
\text { if } .3 M V>\frac{U V B}{\mu_{1}}
$$

and

$$
S=\frac{P V E}{1+.3 \gamma_{2} / \mu_{1}} \quad \text { if } .3 \mathrm{MV}<\frac{\mathrm{UVB}}{\mu_{1}}
$$

Mistakenly estimating a model which assumes $\mu_{1}=1$ when $\mu_{1}$ is in fact less than one does not produce a coefficient of the form $\gamma_{1} / \mu_{1}$ since the classification of the observations is incorrect. However, there will still be a tendency to overestimate the absolute magnitudes of $\gamma_{1}$ and $\gamma_{2^{\bullet}} 7,8$ 
One alternative hypothesis is that market participants view large unfunded liabilities as indicative of financial mismanagement or other incompetent behavior by the firm's managers. This signalling hypothesis can be represented by

$$
M V=P V E-f(U V B)
$$

with $\mathrm{f}^{\prime}<0$. If each increase in UVB is viewed as increasingly ominous then $f^{\prime \prime}<0$.

On the other hand, market participants may feel that low UVB will ultimately be paid but increasing amounts of UVB are increasingly unlikely to be met for reasons unrelated to the $30 \%$ rule. In this case $f^{\prime}<0$ but $f^{\prime \prime}>0$. To test this hypothesis against the signalling hypothesis, I added a term of the form (UVB/A) ${ }^{2}$ to the Variant 2 equation. This term was insignificant but positive (log 1 ikelihood $=-2.37)$ favoring a view that each successive increase in UVB is felt to be less important in relation to previous increases. Thus the signalling hypothesis is not supported. Further this likelihood value is far less than that of the Variant 1 specification. Thus the squared term may merely proxy the discrete break at the $30 \%$ rule (Figure 1 ). The most attractive interpretation of the econometric results is, therefore, that

1. 1iabilities above some discrete level do not diminish the value of a firm's shares and this effect does seem to be associated with the PBGC $30 \%$ rule and

2. the stock market believes pension liabilities as reported in financial statements are understated. 
This paper therefore provides evidence that ERISA, by relieving firms of the responsibility for part of UVB without providing for alternative funding, may contribute to a fall in aggregate saving. Equity values appear unaffected by the part of UVB in excess of $.3 \mathrm{MV}$. A clear conclusion is that one can no longer accept the naive (Variant 2) results obtained by previous researchers and used by Feldstein (1978) to discuss the linkage between UVB and aggregate saving. 


\section{FOOTNOTES}

1. Vesting is the employee's right, on termination of employment prior to retirement, to all or part of the pension benefits which have accrued on his behalf under the pension plan's benefit formula. Usually the actual payment of these benefits will be deferred until he reaches retirement age. In rare instances there may be provision for a lump sum settlement at the time of termination.

A pension plan is incompletely funded if the value of assets in the pension fund is less than the accumulated vested pension benefits. The assets in the pension fund cannot be withdrawn by the employer.

2. Details of the Employee Retirement Income Security Act (ERISA) are given in United States (1974).

3. Discussions with the Value Line analysts indicate that these projections are based on fundamental analysis of the type advocated in standard texts on financial investment, e.g. Graham, Dodd and Cottle (1962).

4. Feldstein (1978) argues that $\gamma_{0}$ should be multiplied by $1 / A$ so that the equations (1la) and ( $1 \mathrm{lb}$ ) when multiplied by $A$ would have a constant term. However, the inclusion of a constant in either specification has little theoretical justification. The usual attempt at interpretation of a constant term in a valuation equation is as a premium for stock issue. This consideration would favor the specification of (11a) and (11b) rather than the Feldstein specification since a stock premium would probably be proportional to the total size of the firm. I tried the Feldstein specification which produced a lower log likelihood value $(-7.44)$ but otherwise similar results to Table 1 , Variant 1.

5. Similar results were obtained using data for 1974 and 1975. The absolute values of $\hat{\gamma}_{1}$ and $\hat{\gamma}_{2}$ fell from 1974 to 1975 and from 1975 to 1976 .

6. Ehrbar (1977) argues that under-reporting may be widespread.

7. If a general understatement of UVB explains the absolute magnitudes of $\hat{\gamma}_{1}$ and $\hat{\gamma}_{2}$ then it appears that either the extent of this understatement or the preception of it has diminished from 1974 to 1976 (see footnote 5).

8. In reality the extent of any understatement varies by firm. Thus estimating $\mu_{l}$ is only a rough solution to this measurement problem. I did however estimate $\mu_{1}$ by choosing different values of $\mu_{1}$ and then estimating the parameters of the model (1la) - (1lc) conditional on each value of $\mu_{1}$. The value of $\mu_{1}$ yielding the highest value of the $\log$ of the likelihood function (22.6) was given by $\mu_{1}=10$. To the best of my knowledge there is no method for producing a t-statistic 
on this type of switching parameter. A case by case adjustment of reported liabilities by a common generally accepted set of assumptions would be extremely difficult and time-consuming. However, this latter approach is clearly the most desirable and should be part of further research in this area. 


\section{BIBLIOGRAPHY}

Arnott, Richard J. and Gersovitz, Mark, "Corporate Financial Structure and the Funding of Private Pension Plans," Joumal of Public Economics, forthcoming.

Ehrbar, A.F., "Those Pension Plans Are Even Weaker Than You Think," Fortune (1977): pp. $104-114$.

Fama, Eugene F., "Risk-Adjusted Discount Rates and Capital Budgeting Under Uncertainty," Journal of Financial Economics, 5 (1977): pp. 3-24.

Feldstein, Martin, "Do Private Pensions Increase National Savings?" Journal of Public Economics, 10 (1978): pp. 277-293.

Goldfeld, Stephen M. and Quandt, Richard E., "The Estimation of Structural Shifts by Switching Regressions," Annals of Economics and Social Measure, 2/4 (1973): pp. 475-485.

Goldfeld, Stephen M., Quandt, Richard E., and Trotter, Hale F., "Maximization by Quadratic Hill-Climbing," Econometrica, 34 (1966): pp. 541-551.

Graham, Benjamin, Dodd, David L, and Cottle, Sidney with the collaboration of Tatham, Charles, Security Analysis, New York: McGraw-Hill, 1962.

Malkiel, Burton G. and Cragg, John C., "Expectations and the Structure of Share Prices," American Economic Review, 60 (1970): pp. 601-17.

Oldfield, George S., "Financial Aspects of the Private Pension System," Journal of Money, Credit and Banking, 9 (1977): pp. 48-54.

Sharpe, William F., "Corporate Pension Funding Policy," Journal of Financial Economics, 3 (1976): pp. 183-193.

Smith, Clifford W., "Option Pricing: A Review" Journal of Financial Economics, 3 (1976): pp. 3-51. 
Tobin, James, "Estimation of Relationships For Limited Dependent Variables," Econometrica, 26 (1958): pp. 24-36.

United States, An Act To Provide for Pension Reform, 1974.

Value Line Investment Survey, New York: Arnold Bernhard, 1974-1976. 